\title{
Mejor no saber....más \\ Sobre la doctrina de la ceguera provocada ante los hechos en Derecho Penal
}

Bernardo Feijoo Sánchez

\section{La normativización del concepto de dolo como solución ${ }^{1}$}

\section{I.1. El dolo eventual}

Las decisiones - de hacer o no hacer- en situaciones de incertidumbre o con una representación con dudas es el terreno en nuestra tradición dogmática del dolo eventual. Nuestra actual praxis punitiva se basa en la idea de que el que contempla la posibilidad de cometer un hecho antijurídico debe eludir tal posibilidad, absteniéndose, actuando en sentido distinto o adoptando medidas adicionales para evitarlo. Si no se adecúa a la situación de incertidumbre comete la modalidad de injusto más grave, la dolosa.

La imprudencia, en sentido contrario, es siempre un error en relación a los elementos del tipo (en los delitos de resultado a los elementos que configuran el riesgo no permitido). Se trata de un error de tipo (mediato o indirecto de prohibición) punible en la medida en la que se entiende que sería evitable con una mayor prestación de atención o se encuentra vinculado a una gestión poco cuidadosa de riesgos. La denominada "imprudencia consciente o con representación" también es un supuesto de error: el autor infravalora el riesgo porque, por ejem-

1 Observaciones a los tres primeros apartados del trabajo del Prof. Ragués. 
plo, sobrevalora sus propias capacidades (que es lo que suele suceder en los homicidios y lesiones en el tráfico viario) o le da un mayor peso a los contra-indicios que a los indicios (el asunto parece turbio, pero tiene una gran confianza personal en quien le hace el encargo). Es decir, el autor imprudente nunca tiene el hecho típico "ante los ojos", ni siquiera con dudas, sino que infravalora las "alarmas" o las "señales de aviso". En estos casos la decisión de actuar u omitir se produce "por error". La posibilidad de cometer el hecho típico es procesada como una posibilidad abstracta o estadística, pero el autor la desecha como posibilidad en el caso concreto ${ }^{2}$.

Actuar por error no es lo mismo que "con error", en la medida en la que nunca abarcamos intelectualmente todas las dimensiones

2 No acierto a concluir si esto coincide con la perspectiva del el Prof. Ragués cuando considera que lo que podría explicar el tratamiento diferenciado del dolo eventual y la imprudencia es que "mientras en el caso del conocimiento la indiferencia tiene como referente concreto el objeto de protección, en el caso del desconocimiento tal indiferencia se manifiesta, de manera más difusa, respecto de todos aquellos intereses susceptibles de ser lesionados".

Este aspecto no es tenido suficientemente en cuenta por MANRIQUE PEREZ, Acción, dolo eventual y doble efecto, Madrid y otras, 2012, pp. 85, 129 s., 135, 272 ss. y passim que pretende "unir el dolo eventual a las formas de los delitos imprudentes", de tal manera que considera que "las consecuencias previstas no forman parte de las razones por las que el agente actúa, no generan compromisos prácticos especificos y su relevancia está paradigmáticamente asociada al reproche por imprudencia" y que el que trata el dolo eventual igual que el dolo directo "debe asumir que los delitos cometidos con imprudencia consciente tienen que ser reprochados de la misma manera que las conductas abarcadas por el dolo eventual, ya que la estructura conceptual en ambos casos es idéntica, i. e. responsabilidad por las consecuencias previstas". En la imprudencia consciente no se puede hablar, sin embargo, de consecuencias previstas de la acción, sino que el autor a lo sumo conoce que está realizando algo que estadísticamente genera ciertas consecuencias, pero en el caso concreto ha desvinculado su acción de tales consecuencias abstractas o estadísticas. Por ejemplo, sabe que ha bebido alcohol pero considera erróneamente que la ingesta de alcohol no afecta seriamente a sus capacidades. No veo que la relevancia y el desvalor sean los mismos que la conducta del conductor que, por una apuesta, circula en sentido contrario $5 \mathrm{~km}$. a $150 \mathrm{~km} / \mathrm{h}$ obligando a los conductores que vienen de frente a desviarse o colisionar. 
de nuestro comportamiento. Si lo tuviéramos que hacer para actuar estaríamos condenados a la inactividad. Se podría decir que siempre actuamos con mayores o menores niveles de ignorancia. Por ello lo decisivo a efectos de imputación no es si el sujeto ignoraba ciertos aspectos, sino si existe un error o defecto cognitivo respecto de los elementos que configuran el hecho como típico, es decir, si el error o la ignorancia tiene relevancia para excluir el dolo.

En este sentido, desde la visión normativa que vengo manteniendo por escrito desde hace quince años ${ }^{3}$, la mayoría de los ejemplos propuestos por el Prof. Ragués son supuestos en los que parece que no plantearía problemas la calificación como dolo eventual aunque los autores se encuentren "en un estado de incertidumbre"4. No se detectan divergencias relevantes entre lo que realmente sucede desde la perspectiva del sistema jurídico y las representaciones del que decide intervenir en el suceso. Siendo esto así, no existen problemas para imputar un injusto doloso en la mayoría de los casos del que participa en una simulación o en un tráfico ilegal. El injusto es doloso siempre que el autor se represente el hecho que va a suceder o los elementos típicos, aunque sea de forma insegura (dolo eventual), de tal manera que con una mínima disposición jurídica ya no se puede confiar en que no se producirá el hecho (en los delitos de resultado lesivo, que no se producirá el resultado como consecuencia del riesgo que se está creando). En "el caso del testaferro profesional que, a cambio de una retribución, acepta figurar como administrador formal de cientos de sociedades de las que no le importa lo más mínimo la actividad real o quiénes son sus verdaderos gestores", el testaferro es consciente de que está participando en una simulación. Ni siquiera la eventualidad es en muchos casos sobre si va a participar en un injusto o no, sino que actúa con un dolo alternativo

${ }^{3}$ La distinción entre dolo e imprudencia en los delitos de resultado lesivo. Sobre la normativización del dolo, Cuadernos de Política Criminal 1998, pp. 269 ss. (El dolo eventual, Universidad Externado de Colombia, 2004); Derecho Penal de la empresa e imputación objetiva, Madrid, 2007, pp. 85 ss.

${ }^{4}$ Sigo opinando, como ya sostuve en CPC 98 -nota 3-, p. 355, que "una correcta construcción de la imputación a título de dolo puede resolver casi todos los casos de «ceguera ante los hechos provocados». 
con respecto a la modalidad de injusto fraudulento (contrato simulado en perjuicio de un tercero, defraudación tributaria, blanqueo de capitales, financiación del terrorismo, etc.). El que es consciente de que se incorpora a una simulación organizada por terceros no necesita saber más para responder por dolo eventual ${ }^{5}$.

El problema dogmático a resolver es el del objeto del dolo en la participación o en los casos de codelincuencia, es decir, qué exige el ordenamiento jurídico que ha de saber el que interviene en un hecho

5 Recomiendo una breve entrevista que se hace en el programa "Salvados" de la cadena de televisión española la Sexta, localizable por internet, de 24 de noviembre de 2013, en el que se entrevista a un parado que se anuncia como testaferro en internet y que confiesa que siempre se sabe que se está participando en algo ilegal, con independencia de que se tengan mayores o menores datos del hecho en el que se está participando.

Es enormemente discutible, por ello, la siguiente afirmación de la STS 34/2007, de 1 de febrero, en relación al testaferro que actúa en un negocio de compraventa simulado a sabiendas: "la participación en un negocio simulado, en principio, no es por sí un hecho típico ni penalmente relevante, salvo el caso del 251.3. En realidad se lo puede considerar un acto neutral desde el punto de vista penal. La doctrina reciente estima que estos actos son comportamientos cotidianos, socialmente adecuados, que por regla general no son tipicos. Tal es el caso del que aparece como adquirente de un inmueble en un contrato de compraventa". Lo que es socialmente adecuado es comprar un inmueble, por lo que es cierto que si un tercero orienta la compraventa en un sentido delictivo es algo irrelevante para la responsabilidad del otro interviniente. Por ejemplo, alguien realmente compra un terreno a precio de mercado sabiendo que el que lo vende quiere alzarse con el dinero en efectivo en perjuicio de sus acreedores o que el que se lo vende a precio de mercado se dedica al narcotráfico. Pero no se puede decir lo mismo cuando alguien aparece falsamente como titular de un inmueble para ocultar a su verdadero titular. En ese caso el testaferro ya no puede decir que solo el tercero, pero no él mismo, están orientando su comportamiento en un sentido fraudulento o de ocultación y que se le está haciendo responder de un hecho ajeno. Lo dicho no significa, sin embargo, que siempre exista dolo eventual. Por ejemplo, puede ser que el testaferro se crea la historia de un amigo o un familiar que le da una explicación plausible de la simulación totalmente ajena a la comisión de un delito. Que el planteamiento de la STS 34/2007 no es correcto lo demuestra que acaba condenado por un blanqueo imprudente. Si realmente fuera socialmente adecuado aparecer falsamente como titular de un bien no cabría ningún tipo de responsabilidad, ni dolosa ni culposa. 
con otros para entender que su participación es dolosa. No se trata más que de una cuestión relativa al alcance del conocimiento con respecto a comportamientos antijurídicos ajenos ${ }^{6}$. Nada nuevo bajo el sol, salvo la demostración de una creciente necesidad de trabajar dogmáticamente en el objeto del dolo en la participación e intervención delictiva a un nivel equivalente al que se ha venido trabajando el objeto del dolo en relación a la autoría en los delitos de resultado lesivo.

Un ejemplo obvio: el que proporciona un cuchillo a otro en una pelea no puede pronosticar con exactitud qué va a pasar. A nadie se le ha ocurrido plantear que su responsabilidad subjetiva depende de que pregunte al que proporciona el cuchillo si piensa mantenerse dentro de los límites de la legítima defensa, lesionar, matar a uno o matar a varios $\mathrm{y}$, en caso de que no lo haga, responda absolutamente de todo lo que suceda con ese cuchillo. Como señala correctamente la STS 258/2007, de 19 de julio (Ponente Enrique Bacigalupo) en un caso de estas características, "en la doctrina reciente es discutido si el dolo del partícipe, especialmente del cooperador, debe ser referido solo a la prestación de ayuda o si además se debe extender a las circunstancias del hecho principal. Sin embargo, la opinión dominante mantiene el último punto de vista, es decir, el de la doble referencia del dolo, el llamado "doble dolo", de caracteres paralelos al requerido para la inducción. Consecuentemente, el dolo del partícipe, como lo viene sosteniendo nuestra jurisprudencia, requiere el conocimiento de la propia acción y, además, de las circunstancias esenciales del hecho principal que ejecuta el autor, en el que colabora. Dicho con otras palabras: el partícipe debe haber tenido una representación mental del contenido esencial de la dirección del ataque que emprenderá el autor. No se requiere, por el contrario, conocimiento de las particularidades del hecho principal, tales como dónde, cuándo, contra quién, etc. será ejecutado el hecho, aunque éstas pueden ser relevantes, en algún caso, para determinar la posible existencia de un exceso, por el que el partícipe no está obligado a responder".

6 Sobre esta cuestión MIRO LLINARES, Conocimiento e imputación en la participación delictiva, Barcelona, 2009, especialmente pp. 209 ss. que, en lo que interesa al tema que nos ocupa, parte del problema de la participación en atentados terroristas como los del 11-S en Nueva York y el 11-M en Madrid sin un conocimiento detallado de los planes de los terroristas. 
Si trasladamos esta doctrina al caso de "quien recibe una importante cantidad de dinero a cambio de transportar una maleta a otra ciudad y prefiere no preguntar exactamente qué es lo que se aloja en el interior", cabe también afirmar que dispone de una representación suficiente de todos los datos relevantes en relación al comportamiento ajeno que convierten su comportamiento en antijurídico. Eventualmente se pueda tratar de dinero, drogas, armas fuera de control legal, material radiactivo, explosivos, material de doble uso, especímenes de flora protegidos y un largo etc. Lo único relevante es que alguna de esas posibilidades se entienda como imprevisible en determinadas circunstancias (transportar una bomba atómica o un cadáver descuartizado) en la medida en la que lo decisivo es que todo este abanico de posibilidades quede abarcado por el potencial lesivo de su contribución de una forma consciente. Como señala el Prof. Ragués en relación a la sentencia del caso United States v. Jewell, leading case en la materia, si alguien no sabe exactamente lo que transporta, pese a tener sospecha de estar haciendo algo ilegal, actúa con dolo eventual con respecto a las posibilidades razonables. Esta parece ser también la opinión del Prof. Ragués y hasta aquí estamos de acuerdo: "pese a su renuncia a conocer, en tales casos el sujeto cuenta ya con un conocimiento básico suficiente para atribuirle tal forma de dolo: así, por ejemplo, en el caso del transporte de la maleta con droga bastará con que el acusado haya sido consciente de la posibilidad de estar transportando dicha sustancia para entender que ha obrado dolosamente, aun cuando no haya llegado a cerciorarse plenamente de todas las características concretas (naturaleza, peso, pureza) del objeto del delito". En este sentido, una de las frases más utilizadas por el Tribunal de Casación español es que "en rigor nos encontramos con un participe en un episodio de trafico de drogas en el que el acusado no muestra un conocimiento equivocado, sino mera indiferencia, como mínimo, con consentimiento en la participación fuese cual fuese la sustancia objeto del transporte. En estos casos el autor solo tiene una duda pero no obra por error o ignorancia ya que sabe que los hechos pueden ser delictivos y sin embargo, acepta realizar la acción, por lo que no se excluye el dolo y se satisface el elemento subjetivo del tipo respecto al componente material del delito"7. Hasta

7 SSTS 359/2008, de 19 de junio; 821/2012, de 31 de octubre, ambas con ulteriores referencias. 
aquí se puede hablar por lo tanto, de un amplio acuerdo doctrinal y jurisprudencial en la doctrina española, salvo, quizás, en casos extremos, y de la constatación de que son necesarias mayores contribuciones que combinen la doctrina del dolo con la doctrina de la participación.

\section{I.2. La ceguera provocada o deliberada ante los hechos.}

La doctrina de la ceguera provocada o deliberada intenta llegar a las mismas conclusiones, pero no trabajando sobre las exigencias del ordenamiento jurídico sobre lo que se debe conocer para responder de forma dolosa, sino cambiando el momento de la "intencionalidad". Mediante tal cambio, se entiende que el sujeto que provoca deliberada o intencionadamente su propia ceguera, porque le interesa para facilitar o hacer más cómoda su decisión moral, es tratado como el que realiza el hecho delictivo de forma intencionada o deliberada. Se trata, formulado en términos dogmáticos más clásicos, de un supuesto de actio libera in causa o de imputación extraordinaria ${ }^{8}$, una especie de "dolo por asunción". El sujeto es así hecho responsable de su ceguera voluntaria, deliberada o intenciona $1^{9} \mathrm{o}$, incluso, como señala el Prof. Ragués en su exposición de la doctrina del willful blindness en el common law, citando la sentencia Spurr v. United States, cuando es consecuencia de una "indiferencia grosera" (grossly indiferent). Para el Derecho Penal sería lo mismo, desde esta perspectiva, el desconocimiento provocado que el conocimiento. Es significativo en este sentido que desde la primera sentencia que adoptó esta doctrina, la STS 1637/1999, de 10 de enero, se haga referencia a que el autor "se pone en situación de ignorancia deliberada".

8 RAGUES I VALLÈS, La ignorancia deliberada en Derecho Penal, Barcelona, 2007, pp. 159 ss.

9 Tiene razón la STS 797/2006, de 20 de julio (Ponente Enrique Bacigalupo) al señalar que las expresiones "ignorancia deliberada" o "ignorancia intencional" no son idiomática ni conceptualmente correctas y que existe contradictio in terminis. Ese es un problema de una mala traducción. Pero ello no debe desviarnos de la cuestión material. La teoría es conceptualmente coherente, la cuestión es si es asumible para fundamentar una condena por el injusto más grave que conoce nuestro ordenamiento, que es el doloso. 
Este adelantamiento de la imputación puede servir para considerar que el hecho no es solo objetiva, sino también subjetivamente imputable. Desde esta perspectiva el planteamiento no encierra grandes novedades. Sin embargo, queda pendiente la cuestión de si es legítimo seguir hablando de una imputación a título de dolo. La actio libera o el actuar precedente tendrá, para ello, que reunir también todas las características que exige el ordenamiento jurídico para poder hablar de responsabilidad dolosa. Si se decide que lo correcto es que en los casos de error pasemos a evaluar los motivos del mismo para delimitar dolo de imprudencia, no alcanzo a ver las razones de fondo por las que solo hay que hacerlo en los casos de provocación de la ceguera y no en todos los casos y con respecto a todas las conductas. Aquí es donde empiezan a surgir los problemas y donde deben quedar al descubierto las "trampas" que oculta la doctrina de la ceguera provocada.

\section{I.3. Inconvenientes de la mal denominada "ignorancia deliberada" desde la perspectiva de lege data}

Los diversos sistemas jurídicos tienen soluciones funcionalmente equivalentes a determinados problemas sociales que, trasladadas a otros ordenamientos, pueden generar disfuncionalidades y fricciones, como cuando se introduce una especie nueva en un ecosistema. Esto es lo que está sucediendo con la malhadada importación de la doctrina de la "ignorancia deliberada" en la jurisprudencia española que da lugar a que el error se trate como dolo cuando "no se sabe porque no se quiere saber" $"$. Quizás esta teoría responda a determinadas

${ }^{10}$ Son cada vez más abundantes las SSTS que parten de que cabe constatar la existencia de dolo eventual, especialmente en supuestos de tráfico de drogas (pero también se ha aplicado a estafas, alzamientos de bienes, blanqueo de capitales, inmigración ilegal, etc.), no solo cuando «al agente le resulta absolutamente indiferente cual sea el resultado de la acción continuando también con su actividad», sino también cuando «a quien pudiendo y debiendo conocer algo no lo conoce $y$, sin embargo, presta su colaboración», de tal manera que «quien no quiere saber que aquello que puede y debe conocer, y sin embargo trata de beneficiarse de dicha situación, si es descubierta no puede alegar ig- 
necesidades que haya que resolver mediante una leal cooperación entre doctrina y jurisprudencia, pero, en la actualidad, más que resolver problemas, se los lleva zafiamente por en medio y, en la mayoría de las ocasiones, en perjuicio del reo. Alejandro Magno cortó el nudo de Gordio con su espada alegando de forma tramposa que tanto monta cortar como desatar, pero los Tribunales de un Estado de Derecho deberían ser más sutiles en la fundamentación de sus sentencias condenatorias. Si solo se tratara de una teoría que llega a conclusiones correctas en sus resultados en casos en los que materialmente existe un dolo eventual, o bien de un mero añadido retórico, tampoco habría que perder mucho tiempo debatiendo sobre este "elemento extraño" en nuestro cuerpo doctrinal. Pero no se trata solo de que sea un cuerpo extraño que aporta más confusión que claridad en nuestros sistemas jurídicos, generando unas enormes dosis de inseguridad en la aplicación del Derecho, sino que su introducción en nuestros sistemas jurídicos encierra peligros que se concretan en consecuencias indeseables entre a las que a mí me preocupan las siguientes:

\section{Se trata de una doctrina que castiga con la pena del delito doloso saltándose las exigencias legales para tal modalidad delictiva}

$\mathrm{El}$ art. $14.1 \mathrm{CP}$ dispensa obligatoriamente un trato más benigno a los que actúan con una errónea representación de los elementos del tipo, y ello con independencia de las valoraciones sobre las razones de tal error. El Código Penal español en el art. 14 solo tiene en cuenta los motivos personales del error para distinguir entre injusto imprudente y ausencia de injusto. Sostener de lege data que no existe un error allí donde el sujeto no quería o no estaba interesado en saber y, por lo tanto, es responsable de su desconocimiento es una normativización contra legem. Según el Derecho positivo español, error sobre los elementos del tipo y dolo son incompatibles, por lo que la equiparación

norancia alguna». Cfr. SS. T. S. 1637/99, de 10 de enero; 1583/2000, de 16 de octubre; 946/2002, de 22 de mayo; 465/2005, de 14 de abril; 1142/2005, de 20 de septiembre; 1410/2005, de 30 de noviembre; 1004/2006, de 11 de octubre; 359/2008, de 19 de junio. 
solo se puede hacer a través de una reforma legislativa expresa pero no por vía judicial ${ }^{11}$.

La imprudencia es también indiferencia, solo que frente a la norma de cuidado. El delito doloso es una indiferencia con un conocimiento mínimo de la situación típica y el delito imprudente sin tal representación. No se trata de ocultar que la distinción entre dolo e imprudencia sea una materia de gran complejidad, pero la teoría de la ceguera voluntaria diluye hasta tal punto los límites que ya no se sabe bien de qué estamos hablando. Si se quiere hacer responder por un delito doloso, el autor debe abarcar intelectualmente el hecho típico ya en el momento de la actio libera o del momento previo en el que se la hace responsable de su ceguera. No puede ser que la referencia a una estructura de responsabilidad "por asunción" convierta sin más la "imprudencia por asunción" en "dolo por asunción", equiparando conductas que para el Derecho vigente se merecen un tratamiento diferenciado.

Se trata de una teoría versarista. Al que se le condena por no querer saber se le hace responsable de todas las consecuencias, hasta de las más imprevisibles

Argumentos como "quien por su propia decisión asume una situación debe asumir las consecuencias de un delictivo actuar" y "el no querer saber los elementos del tipo objetivo que caracteriza el dolo, equivale a querer y aceptar todos los elementos que vertebran el tipo delictivo cometido"12 tienen una preocupante impronta versarista $\mathrm{y}$, por tanto, pueden dar lugar a una imputación excesiva de responsabilidad. La teoría nos retrotrae a los viejos problemas -que parecían superados- que generaba el entendimiento de que la mera voluntariedad de la acción hace que los hechos y resultados se imputen dolosamente (presunción del dolo), de tal manera que nos quedamos con una doctrina de la "provocación voluntaria de la ceguera" que trata igual las consecuencias previstas que las

${ }^{11}$ Para el Derecho alemán ROXIN, Strafrecht. Allgemeiner Teil, Band I, $4^{\mathrm{a}}$ ed., Munich, 2006, 12/34.

${ }^{12}$ SSTS 359/2008, de 19 de junio; 446/2008, de 9 de julio; 464/2008, de 2 de julio; 440/2011, de 25 de mayo; 1044/2011, de 25 de mayo; 157/2012, de

1107 de marzo; 821/2012, de 31 de octubre. 
difícilmente previsibles. Lo que quiero decir creo que se expone muy bien con un ejemplo: en el doble fondo de la maleta de nuestro ejemplo hay una bomba para eliminar a miembros de otra organización, lo cual es desconocido por el que lleva la maleta a pesar de que es consciente de que está transportando algo prohibido. Si se quiere ser consecuente con la literalidad de la teoría, se deberían imputar todas las muertes que deriven de la explosión como homicidios o asesinatos con dolo eventual.

La conclusión es inaceptable porque es necesario que el dolo del partícipe abarque los elementos que configuran la naturaleza del injusto. El que tiene datos de estar participando en un tráfico ilegal o un acto de contrabando conoce lo suficiente para responder, con independencia del objeto con el que se trafique, mientras no se trate de algo fuera de toda previsión. Sin embargo, ello no significa que actúe dolosamente en relación a un evento violento. Por ejemplo, creyendo que transporta drogas para una organización de narcotráfico ya que le han mostrado indicios en ese sentido intencionadamente, en realidad está transportando armas bioquímicas para un terrible atentado terrorista. En el mismo sentido, el que tiene datos de estar participando en una simulación no abarca de manera dolosa estar participando en hechos violentos o intimidatorios. Hay que tener en cuenta la heterogeneidad de los injustos y de las características del hecho principal desde la perspectiva subjetiva.

\section{Problemas desde el punto de vista de la presunción de inocencia}

La mal denominada teoría de la "ignorancia deliberada" permite eludir la prueba de la responsabilidad subjetiva y las exigencias desde el punto del principio de presunción de inocencia con respecto a los elementos subjetivos del delito que se han ido construyendo jurisprudencialmente ${ }^{13}$. La imputación se basa en una valoración sin soporte

13 SSTC 68/1998, de 30 de marzo; 171/2000, de 26 de junio; 137/2002, de 3 de junio; 267/2005, de 24 de octubre; 177/2007, de 4 de junio; 91/2009, de 20 de abril; STS 474/2013, de 24 de mayo, con una amplia y completa exposición de la doctrina del Tribunal Europeo de Derechos Humanos sobre 
fáctico real que da lugar a una inversión de la carga de la prueba: el que es responsable de su desconocimiento responde dolosamente a no ser que pruebe que no fue por falta de interés. Las acusaciones dejan de tener que asumir la carga probatoria de indicios en la medida en la que se abren las compuertas a la posibilidad de condenar por dolo si no hay contraindicios. Si se me permite el sarcasmo, se trata de una institución que permite la condena por dolo sin tener que probar el dolo, sino solo la existencia de una provocación voluntaria como, por ejemplo, aceptar un encargo.

Esto no es solo purismo dogmático ante una institución que a determinados teóricos nos resulta extraña. Algunos magistrados de la Sala Segunda del Tribunal Supremo han percibido los peligros de esta doctrina y han alertado sobre los mismos. Por ejemplo, la Sentencia del Tribunal Supremo 57/2009, de 2 de febrero (Ponente Manuel Marchena Gómez), pone en entredicho esta figura objetando certeramente que

"Es cierto que la jurisprudencia de esta Sala, desde la STS1637/199, de 10 de enero ha venido sosteniendo que quien se pone en situación de ignorancia deliberada, es decir no querer saber aquello que puede y debe conocerse, y sin embargo se beneficia de esta situación, está asumiendo y aceptando todas las posibilidades del origen del negocio en el que participa, y por tanto debe responder de sus consecuencias. Esta idea ha venido reiterándose en otros muchos pronunciamientos de los que las SSTS 446/2008, 9 de julio, 464/2008, 2 de julio, 359/2008, 19 de junio y 1583/2000, 16 de octubre, no son sino elocuentes ejemplos. Tampoco falta algún pronunciamiento que reacciona frente a lo que considera una contradictio in terminis, pues tales expresiones -ignorancia deliberada o de ignorancia intencional- no resultan ni idiomática ni conceptualmente adecuadas, dado que si se tiene intención de ignorar es porque, en realidad, se sabe lo que se ignora. Nadie puede tener intención de lo que no sabe (cfr. STS 797/2006, 20 de julio).

Acaso convenga, sin embargo, no llevar esa idea más allá de lo

las exigencia de prueba de los elementos subjetivos y fácticos del dolo para desvirtuar el derecho a la presunción de inocencia. 
que autoriza su propio significado. De lo contrario, corremos el riesgo de avalar un entendimiento de aquella doctrina que, por la vía práctica, ofrezca a los Tribunales de instancia un instrumento más que útil para eludir el deber de motivación respecto del tipo subjetivo y, sobre todo, obviar la prueba del conocimiento sobre el que se construye el dolo eventual. Y es que hoy nadie cuestiona, tanto desde las teorías cognitivas como volitivas del dolo, que solo aquel que ejecuta la acción típica con alguna forma de conocimiento de los elementos del tipo objetivo, puede hacerse merecedor de pena.

Sustituir el conocimiento o la representación de los elementos del delito por la prueba de que el sujeto activo ha evitado deliberadamente abarcar esos elementos, puede implicar nuestro apoyo a una verdadera desnaturalización del desafío probatorio que incumbe a las acusaciones. En supuestos como el que nos ocupa, la condena del acusado solo puede basarse en lo que éste sabía, no en lo que debió conocer. El reproche penal por lo que se debió conocer y, sin embargo, no se conoce, no puede servir, sin más, de fundamento para la afirmación del dolo".

El propio ponente ha reiterado estos argumentos en la más cercana sentencia 234/2012, de 16 de marzo, y ha señalado la misma solución que se propugna en este trabajo; es decir, una adecuada teoría del dolo eventual, sin necesidad de ocultar ficticiamente los problemas, convierte en superfluas otro tipo de construcciones que generan más problemas que los que resuelven y que pueden ser fuente de soluciones injustas en la medida en la que permiten que la pena no refleje adecuadamente el desvalor de la conducta del sujeto:

"La experiencia ofrece numerosos ejemplos en los que se producen verdaderas situaciones de ignorancia deliberada. Son casos en los que el autor, pese a colmar todas las exigencias del tipo objetivo, ha incorporado a su estrategia criminal, de una $u$ otra forma, rehuir aquellos conocimientos mínimos indispensables para apreciar, fuera de toda duda, una actuación dolosa, si quiera por la vía del dolo eventual. De esa manera, se logra evitar el tratamiento punitivo que el CP reserva a los 
delincuentes dolosos, para beneficiarse de una pena inferior -prevista para las infracciones imprudentes-o de la propia impunidad, si no existiera, como sucede en no pocos casos, una modalidad culposa expresamente tipificada.

De lo que se trata, en fin, es de fijar los presupuestos que permitan la punición de aquellos casos de ignorancia deliberada en los que se constate la existencia de un acto de indiferencia hacia el bien jurídico que sugiera la misma necesidad de pena que los casos de dolo eventual en su sentido más estricto. Para ello sería necesaria la concurrencia de los siguientes requisitos:

$1^{\circ}$.- Una falta de representación suficiente de todos los elementos que definen el tipo delictivo de que se trate. Esa falta de representación, si es absoluta, nunca podrá fundamentar la imputación subjetiva a título de dolo. Los supuestos abarcados estarán relacionados, de ordinario, con la conciencia de que se va a realizar, con una u otra aportación, un acto inequívocamente ilícito. La sospecha puede incluso no llegar a perfilar la representación de todos y cada uno de los elementos del tipo objetivo, al menos, con la nitidez exigida de ordinario para afirmar la concurrencia del elemento intelectual del dolo. Sin embargo, sí ha de ser reveladora de una grave indiferencia del autor hacia los bienes jurídicos penalmente protegidos, pues, pese a representarse el riesgo que su conducta puede aparejar, no desiste del plan concebido.

$2^{\circ}$.- Una decisión del sujeto de permanecer en la ignorancia, aun hallándose en condiciones de disponer, de forma directa o indirecta, de la información que se pretende evitar. Además, esa determinación de desconocer aquello que puede ser conocido, ha de prolongarse en el tiempo, reforzando así la conclusión acerca de la indiferencia del autor acerca de los bienes jurídicos objeto de tutela penal.

$3^{\circ}$.- Un componente motivacional, inspirado en el propósito de beneficiarse del estado de ignorancia alentado por el propio interesado, eludiendo así la asunción de los riesgos inherentes a una eventual exigencia de responsabilidad criminal. En el presente caso, es claro que se colman los requisitos expuestos, hasta el punto de que ninguna duda puede albergarse acerca del dolo eventual -expresado en su indiferencia respecto 
del menoscabo del bien jurídico protegido- con el que Aurelio trasladó al zulo de la localidad de Valgañón la mochila en cuyo interior se hallaba el subfusil. La morfología de los objetos que fueron trasladados, asociada a la funcionalidad predicable de los zulos utilizados por ETA para la consecución de sus fines, no hace difícil representarse y aceptar con indiferencia que a lo que se estaba contribuyendo era a la ocultación de armas que luego podían ser utilizadas en los atentados de la banda terrorista".

La condena con base en los hechos declarados como probados es justa en este caso porque el sujeto ejecutó su decisión teniendo una representación suficiente del hecho que estaba realizando, con independencia de cuál fuera su intención o interés. Es evidente que cuando alguien participa en las actividades de una organización terrorista o de una organización criminal que, por sus características, permiten contribuciones puntuales y muy compartimentadas carece de un conocimiento completo del alcance de su conducta. Ello no afecta al dolo si conoce todos los datos relevantes para conocer el significado de su propia conducta y saber, por ejemplo, que está ocultando un arma en un zulo. No hace falta recurrir a la mal denominada doctrina de la "ignorancia deliberada", como hace alguna otra resolución próxima en el tiempo ${ }^{14}$ que, como ya se ha expuesto, encierra enormes peligros de arbitrariedad.

Creo que un ejemplo real vale más que una extensa exposición argumentativa. La STS 496/2006, de 3 de mayo, confirma la condena de un camionero por transportar mercancías robadas (receptación) y su absolución por tenencia y tráfico de explosivos porque en el mismo camión transportaba en un paquete elementos que permitían construir artefactos caseros. En este caso no se trata de que el sujeto no supiera lo que estaba llevando, sino que estaba convencido de que solo transportaba mercancía robada. La sentencia de instancia considera probado que el conductor conocía el origen ilícito de las mercancías a efectos del delito de receptación, pero manifestó "serias dudas" en relación al conocimiento de la llevanza de explosi- 
vos. El Ministerio Fiscal recurrió la absolución esgrimiendo que "la misma argumentación que el tribunal de instancia dedica a la acreditación del conocimiento sobre el origen ilícito de las mercancías que fundamentan el delito de receptación, sirve para afirmar el conocimiento del transporte de los explosivos y, al tiempo, afirma ese conocimiento desde el principio que invoca de "ignorancia deliberada», en cuya virtud, en términos de la STS 946/2002, de 22 de mayo, "quien no quiere saber y puede y debe conocer, $y$ sin embargo trata de beneficiarse de dicha situación, si es descubierto, no puede alegar ignorancia», afirmando que el acusado, admitió la llevanza de un paquete, como habia realizado respecto a otros, conociendo la antijuridicidad de su conducta para entregarlo en el extranjero a personas que conocía". La absolución se mantiene afirmando que si bien

"Es cierto que esta Sala, en una reiterada jurisprudencia ha afirmado que el conocimiento sobre la llevanza de objetos de tráfico ilícito se ha afirmado desde la clandestinidad de la conducta, desde el beneficio económico que obtiene el transportista y desde la propia conducta desplegada, en este caso, el aprovechamiento del camión para la llevanza de mercancías de procedencia ilícita. Se trata de inferencias racionales sobre un elemento subjetivo, el conocimiento de la antijuridicidad de la acción que resulta de indicios acreditados. En el presente supuesto el tribunal de instancia afirma tener serias dudas sobre el conocimiento del transporte de los explosivos, efectivamente transportados y esas dudas las sostiene sobre tres elementos principales: en primer lugar, la ocultación en un paquete de la sustancia explosiva; las declaraciones del acusado afirmando que de saberlo no la hubiera transportado en la cabina del camión, sino en la caja para no correr riesgos; y, sobre todo, del resultado de una intervención telefónica, en la que, un acusado rebelde habla con una tercera persona y acuerdan que la mercancía fuera bien envuelta para que el transportista desconociera su contenido. Así lo fundamenta la sentencia y es una expresión razonable de las dudas sobre el conocimiento de la llevanza de la sustancia explosiva". 
Mi sensación personal es que el camionero del ejemplo se libra de la condena por tenencia y tráfico de explosivos por pura casualidad, gracias a que una intervención telefónica de la policía aporta pruebas de su falta de conocimiento. La doctrina de la "ignorancia deliberada" hubiera llevado a la condena sin un especial esfuerzo probatorio por parte del Ministerio Fiscal (le bastó en su recurso con ondear la bandera de la "ignorancia deliberada") y la doctrina no se aplica, sencillamente, porque en este caso existe -casualmente- prueba a favor del reo. Personalmente me causa enorme desazón pensar qué hubiera sucedido de no haber existido la intervención telefónica.

\section{II. ¿Problemas mal resueltos?}

El Prof. Ragués considera en el apartado IV de su trabajo que la actual doctrina del dolo eventual tiene pendiente por resolver dos grandes problemas: Uno sería que un concepto excesivamente amplio de dolo no refleje la diversa culpabilidad de los autores, al cobijar "bajo un mismo título de imputación subjetiva -y, en principio, se castiguen con la misma pena-supuestos muy distintos desde el punto de vista del grado de implicación subjetiva del sujeto en el hecho". Otro estaría relacionado con déficits preventivos: puede haber supuestos excepcionales "en los que, de manera intencionada, el sujeto haya evitado adquirir incluso aquellos conocimientos mínimos que requiere el dolo eventual". Paso a tratar estas dos cuestiones, empezando por la última.

\section{II.1. La desvinculación del conocimiento como solución a las insuficiencias preventivas del dolo eventual.}

Según el Prof. Ragués, "el planteamiento mayoritario en Derecho continental considera que la falta de conocimiento -siquiera eventual-de la concurrencia en un determinado comportamiento de los elementos de una figura delictiva impide considerar el hecho como doloso, lo que lleva a la impunidad o, cuando la ley lo permita, a castigar la conducta como imprudente". Esta posición le parece insatisfactoria e injustificada en ciertos casos, en la medida en la que conduce a la impunidad o a una atenuación im- 
portante de la pena si existe una modalidad imprudente específicamente tipificada, y ello le resulta más intolerable en aquellos casos en los que "el individuo ha buscado beneficiarse de su estado de ignorancia para eludir responsabilidades". Su planteamiento queda perfectamente ilustrado con el ejemplo del individuo que da instrucciones para no admitir comunicaciones oficiales, planteando que podría realizar una desobediencia dolosa frente a un juzgado que le requiere documentación pasado un tiempo.

Considera que ciertos casos de ceguera provocada que obedecen a un grave desinterés por parte del autor tendrían un trato más adecuado como delitos dolosos a pesar del desconocimiento. Es decir, que, al igual que sucede en el Código Penal español con causas de exclusión de la culpabilidad como el trastorno mental transitorio (art. $20.1^{\circ}$ ) o la intoxicación plena (art. $20.2^{\circ}$ ), el error no atenúe o exonere si "hubiese sido provocado por el sujeto con el propósito de cometer el delito o hubiera previsto o debido prever su comisión", es decir, si el déficit de conocimiento es de su responsabilidad en la medida en la que deriva de una disposición jurídica deficiente. Según el Prof. Ragués no habría problema en trasladar estas cláusulas referidas a la inimputabilidad a la regulación del error aunque el legislador no lo haya dispuesto así.

Sin duda, como señala en su apartado IV.2., el autor más representativo y sugerente con respecto a este tipo de planteamientos ha sido $\mathrm{JAKOBS}^{15}$, con contribuciones también muy interesantes en

15 Por diversos lugares, y sin ánimo de exhaustividad: Strafrecht. Allgemeiner Teil. Die Grundlagen und die Zurechnungslehre, $2^{\mathrm{a}}$ ed., Berlín, 1991, 8/5 ss., con nota 9; Über die Behandlung von Wollensfehlern und von Wissensfehlern, Zeitschrift für die gesamte Strafrechtswissenschaft 101 (1989), p. 532; El principio de culpabilidad, Anuario de Derecho Penal 1992, pp. 1058 s.; Sociedad, norma y persona en una teoría de un Derecho penal funcional, Madrid, 1996, pp. 55 ss.; Imputación jurídico-penal, desarrollo del sistema con base en las condiciones de la vigencia de la norma, Poder Judicial no 49 (1998), pp. 303 s.; Gleichgültigkeit als dolus indirectus, Zeitschrift für die gesamte Strafrechtswissenschaft 114 (2002) (existe una traducción de PEREZ DEL VALLE en Dogmática y ley penal. Libro Homenaje a Enrique Bacigalupo, Madrid, 2004), pp. 584 ss.; Sobre la normativización de la dogmática jurídico-penal, Madrid, 2003, pp. 85 ss. Sobre ceguera ante los hechos, LESCH, Dolus directus, indirectus und even- 
Mejor no saber....más. Sobre la doctrina de la ceguera ...

este sentido de su discípulo PAWLIK, que ha acabado asumiendo este tipo de planteamientos de su maestro en la obra que compendia su visión del Derecho Penal, "Das Unrecht des Bürgers"16 que, sin duda -con independencia de no compartir sus planteamientos- es una de las obras teóricas clave de estos primeros años del siglo XXI. JAKOBS lleva muchos años defendiendo que la "ceguera ante los hechos" (Tatsachenblindheit) debe tener el mismo tratamiento que la legislación, doctrina y jurisprudencia alemana vienen otorgando a la

tualis, Juristische Arbeitsblätter 1997, pp. 802 ss. y Der Verbrechensbegriff: Grundlinien einer funktionalen Revision, Colonia, 1999, pp. 140 ss. En contra, la doctrina dominante: KINDHÄUSER, Gleichgültigkeit als Vorsatz?, en Menschengerechtes Strafrecht, Festschrift für Albin Eser, Munich, 2005, pp. 345 ss., 356 s., en lo que creo que es la crítica más acertada contra la propuesta de JAKOBS; PUPPE, Strafrecht als Kommunikation. Leistungen und Gefahren einen neuen Paradigmas in der Strafrechtsdogmatik, en Festschrift für Gerald Grünwald, Baden-Baden, 1999, pp. 483 s.; SACHER, Sonderwissen und Sonderfähigkeiten in der Lehre vom Straftatbestand, Berlín, 2006, p. 175 y passim, en la línea de su maestro SCHÜNEMANN; la misma, Systemtheorie und Strafrecht. Kritik der rollenbezogenen Zurechnungslehre, Zeitschrift für die gesamte Strafrechtswissenschaft 118 (2006), pp. 585 ss.; SCHNEIDER, Kann die Einübung in Normanerkennung die Strafrechtsdogmatik leiten? Eine Kritik des strafrechtlichen Funktionalismus, Berlín, 2004, pp. 118 ss.; SCHÜNEMANN, Temas actuales y permanentes del Derecho penal después del milenio, Madrid, 2002, pp. 99, 106 s., que desde Die Objektivierung von Vorsatz und Schuld im Strafrecht, Chengchi Law Review, Vol. 50, Mayo 1994. Sonderausgabe zum Taiwanesisch-Deutsch-Spanischen Strafrechtlichen Symposium, p. 265 denomina la posición de JAKOBS como «la total objetivación postmoderna del dolo»; VOGEL, Normativierung und Objektivierung des Vorsatzes?, Goltdammer's Archiv 2006, pp. 386 ss., especialmente 388 s.

JAKOBS parece querer recuperar la vieja idea aristotélica (Ética Nicomáquea, Libro III y Libro V, apartado 8 in fine) de que no es lo mismo la acción con ignorancia que con ignorancia y por ignorancia, siendo solo disculpable y, por tanto menos merecedora de pena, esta última. Cfr. ZStW 114, p. 589, nota 11. Debido a ello intenta recuperar la antigua tradición escolástica del dolus indirectus entre conocimiento e imprudencia (ZStW 114, pp. 584 ss.; Dolus malus, InDret Penal 4/2009, pp. 5, 18 s.).

16 Ya había adelantado tales planteamientos, al igual que otros muchos de la misma obra, en Person, Subjekt, Bürger. Zur Legitimation von Strafe, Berlín, 2004, pp. $85 \mathrm{~s}$. 
"ceguera ante el Derecho", de tal manera que el error no siempre atenúe y que, en todo caso, la atenuación dependa de la mayor o menor fidelidad al Derecho del autor y no de lo que esté dispuesto a conocer.

Como señala el Prof. Ragués, los problemas que preocupan a JAKOBS y en los que centra su exposición no tienen que ver con una ceguera intencionada, sino con una falta de interés por las normas o una indiferencia frente a la norma que le impide al sujeto percibir ciertos datos (al que no profesa la religión católica le da igual cuando empiece la cuaresma en sociedades en las que como la española el ceremonial católico ha dejado de ser un referente que protagonice la vida social). Es decir, lo que ha puesto de manifiesto JAKOBS es que ciertos déficits cognitivos tienen su origen en déficits volitivos. El problema es real y no cabe duda de que JAKOBS habilita una solución que podría ser válida. Es fácil percibir tal problema si tenemos en cuenta una evidencia neurocientífica como que los aspectos cognitivos o intelectuales y los afectivos o emocionales de los procesos mentales no operan separadamente, por lo que las emociones guían nuestra representación de la realidad y pueden existir sesgos cognitivos derivados de un desinterés por observar el Derecho (al igual que existen sesgos cognitivos que tiene su origen en una enfermedad mental). Las emociones pueden determinar las experiencias pasadas y conocimientos disponibles en un momento dado, así como la percepción de la situación ${ }^{17}$. Las representaciones y planificaciones de los individuos se ven condicionadas por su propio mundo emocional y de sentimientos. Si esto es así, los individuos pueden tener "puntos ciegos" derivados de una actitud general de desinterés frente al Derecho. Si tenemos en cuenta la expresión popular de que la codicia ciega o, como decía Joseph Conrad, "no hay credulidad tan ansiosa y ciega como la credulidad

${ }^{17}$ No comparto la opinión de ROXIN, Zur Normativierung des dolus eventualis und zur Lehre der Vorsatzgefahr, en Hans-Joachim Rudolphi-FS, Neuwied, 2004 , p. 257, de que solo a través de una teoría volitiva se puedan tratar de una forma valorativamente adecuada este tipo de realidades. La solución pasa por una mayor normativización del dolo, pero no necesariamente por una normativización del elemento volitivo hasta convertirlo en un mero criterio normativo de imputación difícilmente reconocible. 
de la codicia", también habrá otras emociones como el odio vinculado a prejuicios que cieguen aspectos de la realidad. Excepcionalmente, una disposición jurídica defectuosa o un sesgo emocional pueden hacer que el sujeto no procese adecuadamente datos de una situación que un ciudadano con una adecuada disposición jurídica habría percibido claramente. El problema no estaría ya en las decisiones morales a corto plazo y sus características, sino en las decisiones morales a largo plazo que tienen que ver con la actitud que el autor adopta frente al Derecho o frente a ciertos aspectos del ordenamiento.

JAKOBS y PAWLIK son coherentes en sus planteamientos con su visión del Derecho Penal, tanto del fundamento de la pena como de la teoría de la imputación jurídico-penal. Si se quiere asumir tal planteamiento hay que asumirlo al completo: lo único que importa es la mayor o menor fidelidad jurídica y la pena responde a la correspondiente falta de fidelidad jurídica. Si la función del Derecho Penal es estabilizar en la generalidad de la población la fidelidad al Derecho a largo plazo o como plan vital, lo decisivo deja de ser qué tipo de deberes infringió el sujeto y pasa a ser en exclusiva la valoración de la fidelidad manifestada en el hecho. Todo se valora desde este prisma valorativo, por lo que las características de las decisiones puntuales pasan a ser irrelevantes. La imputación subjetiva carece de entidad por sí misma y no es más que un indicador de la existencia de un quebrantamiento de la norma en virtud de un defecto de fidelidad suficiente como actitud vital (por ello el que tiene una permanente actitud vital contraria a Derecho es tratado como enemigo y no como persona en Derecho). Ello obliga, en sentido contrario a la teoría del delito dominante en la dogmática europea continental y a Códigos Penales como el español, a considerar que no existe distinción entre injusto y culpabilidad y, por tanto, entre dolo y conocimiento de la antijuridicidad $^{18}$. La culpabilidad es una categoría que acaba absor-

${ }^{18}$ Representativo JAKOBS, InDret Penal 2009 (nota 15), que deja claro en p. 5 que "no se coloca un fenómeno psicológico (conocimiento) al lado de otro (enemistad); se argumenta normativamente, a partir de la exigencia de fidelidad jurídica, e incluso el conocimiento constituiría, desde esta perspectiva, únicamente el indicio de la existencia de un déficit, precisamente de fidelidad jurídica". 
biéndolo todo ${ }^{19} \mathrm{y}$, por ello, todas las instituciones de la teoría jurídica del delito son indicadores de una mayor o menor falta de fidelidad al Derecho, que es el elemento central de la imputación jurídico-penal y del castigo. Las categorías dogmáticas tradicionales (autoría/participación, dolo/imprudencia, etc.) quedan convertidas solo en factores cuantitativos de individualización de la pena. Si se quiere seguir esta vía para resolver un problema puntual hay que adoptar como válidas estas decisiones fundamentales.

No creo que esta sea la vía que se pretende seguir en el trabajo del Prof. Ragués. Por ello estoy de acuerdo con él en que "en aquellos casos en los que el sujeto ha contado con una sospecha inicial de que su conducta presente o futura podría resultar lesiva para algún interés penalmente relevante pero ha preferido mantenerse en un estado de ignorancia como una estrategia para, llegado el caso, poder alegar dicha ignorancia en su descargo cabe advertir una necesidad de sanción similar a la de los casos de dolo eventual y, desde luego, superior a los supuestos habituales de negligencia". Pero no porque sean casos similares o valorativamente equivalentes a los de dolo eventual en los que se da muestras de un desinterés equivalente por el Derecho, sino porque son supuestos de dolo eventual. Actúa con dolo el que ha decidido seguir adelante sin despejar sospechas racionalmente fundadas o a pesar de la presencia de indicios racionales del significado de su conducta. El que busca eludir responsabilidades no tiene "puntos ciegos" si en el momento de provocar su ceguera dispone de todos los datos relevantes (con más o menos dudas o certidumbres) ya que esté previendo esa posibilidad con base en los datos de que dispone. Solo el que es consciente de la antijuridicidad de su conducta se esconde de la policía o crea concretas líneas de defensa preventivas para el caso de que le pillen o le detengan. Evidentemente, no todo el que actúa con dolo se ve sometido a una responsabilidad subjetiva sin límites. La decisión dolosa tiene que abarcar las consecuencias de la conducta o su vinculación con un hecho delictivo concreto. Incluso el

${ }^{19}$ Básicos JAKOBS, Der strafrechtliche Handlungsbegriff, Munich, 1992, pp. 43 s. y Handlungssteuerung und Antriebssteuerung. $\mathrm{Zu}$ Hans Welzels Verbrechensbegriff, en Strafrecht, Biorecht, Rechtsphilosophie, Festschrift für Hans-Ludwig Schreiber, Heidelberg, 2003, pp. 952 ss. 
que provoca dolosamente su ceguera posterior puede verse afectado por algún error sobre algún elemento del hecho típico que excluya un hecho doloso o una participación dolosa. Por ejemplo, el que quiere evitar la previsible comunicación de que tiene que entregar su carnet de conducir porque ha perdido todos los puntos, no dispone de dato alguno de que vaya a recibir un requerimiento judicial.

No comparto la idea de que "en ordenamientos como el argentino o el español no parece que existan problemas insalvables de legalidad para incluir estos supuestos en el concepto de dolo, una expresión muy abierta, de carácter eminentemente técnico y de la que no existe definición legal, aunque conviene tener presente que la inclusión de semejante casos en el concepto de dolo impedirá seguir definiendo esta figura a partir del conocimiento". No me puedo pronunciar sobre el Derecho argentino pero, aunque, a diferencia de otros ordenamientos, el Código Penal español no ofrece una definición del dolo, deja claro que todo error sobre la situación típica -vencible o invencible- lo excluye.

Creo que las insuficiencias preventivas exigen cambios legislativos, pero no en el sentido que parece apuntar el Prof. Ragués. Es conocido el viejo argumento contra el sistema de numerus clausus en la imprudencia de que genera lagunas de punición y que de facto provoca que la jurisprudencia extienda el alcance del dolo eventual. La solución no está en que el legislador bendiga una práctica perversa, sino en aligerar o reducir las tensiones que generan ciertos "casos límite". En este sentido hace algo más de 15 años que propuse una solución consistente en crear una categoría intermedia de imprudencia grosera o grave desconsideración ${ }^{20}$-la denominación es lo de menos- que permitiera imponer una pena más grave que la adecuada a los supuestos ordinarios de imprudencia, con especiales exigencia de motivación, en aquellos casos en los que, como sucede en el Código Penal español, las diferencias de pena no se correspondan con el desvalor que se merecen las conductas. Es cierto que para la inmensa mayoría de los

${ }^{20}$ La imprudencia en el Código Penal de 1995 (cuestiones de lege data y de lege ferenda), Cuadernos de Política Criminal 1997, pp. 352 ss.; CPC 98 -nota 3-, pp. $353 \mathrm{~s}$. 
homicidios por imprudencia grave una pena de 1 a 4 años de prisión es más que suficiente (sobre todo teniendo en cuenta que el límite de la suspensión de la ejecución y de la sustitución por penas no privativas de libertad es de 2 años, lo cual es un poco incongruente). Pero el salto, en caso de dolo, a una pena de 10 a 15 años no siempre tiene sentido si tenemos en cuenta que existen casos de error en los que un sujeto con una disposición jurídica adecuada no habría incurrido en la representación errónea o sufrido los mismos sesgos cognitivos del infractor o en los que la inmensa mayoría de las personas habría procesado el hecho de otro modo (la jurisprudencia española castiga inadecuadamente por dolo eventual supuestos en los que un ciudadano razonable se habría dado cuenta de la gravedad del riesgo o de la seriedad de la situación aunque el sujeto concreto ni se lo plantee). La jurisprudencia nos enseña como existen situaciones en las que cualquiera diría: pero, ¿Cómo no se ha dado cuenta? ¡Cualquiera se hubiera dado cuenta! En muchos ordenamientos como el español se puede apreciar una excesiva rigidez para tratar adecuadamente estos casos excepcionales. Una solución posible y de amplia aceptación sería la introducción de una figura como la propuesta en la parte especial, no solo en los tipos que ya tienen contemplado un tipo imprudente como una modalidad agravada, sino también mediante nuevos tipos específicos, pero en los que más que una imprudencia estándar quede claro que se está castigando una imprudencia especialmente cualificada por los datos o indicios que el autor tenía a su alcance, aunque no los procesara intelectualmente, o por la entidad del desprecio a sus deberes profesionales. Un ejemplo lo podemos encontrar en el Código Penal español donde el blanqueo de capitales doloso tiene contemplada una pena de prisión de seis meses a seis años y multa del tanto al triplo del valor de los bienes, mientras la pena por imprudencia grave es de una multa equivalente con pena de prisión de seis meses a dos años. Ante el trato punitivo equivalente creo que no es adecuado entender aquí "imprudencia grave" con el mismo sentido que en otros tipos penales, sino de manera más restringida en el sentido expuesto. Este tipo de soluciones en la parte especial permiten evitar modificaciones de una configuración de la responsabilidad subjetiva de sólida tradición que 
pueden acabar siendo disfuncionales o de consecuencias imprevisibles. Quien crea que ello sería una cesión a necesidades preventivas y una expansión ilegítima del Derecho Penal, debe pensar que cuando la solución no entra por la puerta del Parlamento acaba entrando por la ventana de atrás de los Palacios de Justicia y, como ya he expuesto, con enormes peligros para elementos estructurales del sistema jurídico continental.

\section{II.2. Dolo eventual y pena proporcional al hecho}

Ante semejante concepto de dolo sobredimensionado que deja prácticamente fuera solo los supuestos de torpeza, impericia o lo que el Prof. Ragués denomina "debilidad moral", se busca una solución en el ámbito de lo que éste denomina "tratamiento penológico", que permita "la gradación de las consecuencias jurídicas por razones de imputación subjetiva", es decir, se traslada la solución al ámbito de la determinación o la cuantificación de la pena. "El hecho de que bajo un único concepto de dolo -y, en principio, con la misma respuesta punitiva-deban incluirse situaciones tan diversas entre sí como la intención, la mera representación del riesgo o ciertos casos de desconocimiento provocado permite afirmar que esta figura no solo está conceptualmente "sobrecargada", sino que, además, su aplicación plantea importantes problemas de proporcionalidad". Ciertamente, si la categoría del dolo abarca desde el dolo intencional hasta errores por indiferencia existe el problema de que bajo la denominación de dolo se cobijarán situaciones tan distintas, que parecen hacer inevitables mayores subdivisiones. Pero ese es un problema que plantea la ampliación del ámbito del dolo a supuestos en los que el sujeto actúa con base en un error o defecto de representación. Si se mantiene una distinción entre dolo e imprudencia basada en lo que el sujeto se representa a la hora de tomar su decisión de actuar o de omitir la diferencia de pena representará una diferencia esencial: el autor imprudente es alguien que no se encuentra de partida personalmente tan alejado del Derecho como el autor doloso porque su vinculación subjetiva con el hecho es menor. Forma parte de nuestra visión de las relaciones sociales, que un "no me di cuenta" sincero exonere o atenúe la respon- 
sabilidad o el reproche personal. Esto se puede trasladar a procesos sociales de imputación y desvalor. El que actúa con dolo eventual ya no puede decir sinceramente "no me di cuenta"; a lo sumo, "no me lo tomé en serio aunque debería haberlo hecho".

En este punto el Prof. Ragués se separa de un planteamiento normativista y parece que quiere tratar el dolo como un "estado mental". Ello tiene una serie de problemas. Uno primero es de carácter teórico y es que, como he defendido en varias ocasiones, la teoría de la determinación de la pena tiene que guardar una coherencia interna con el fundamento de la imputación jurídico-penal. Desde el punto de vista práctico me parece arbitrario establecer, aunque solo sea a efectos de individualizar la pena, una distinción basada en los elementos volitivos o afectivos de la conducta o en una combinación de elementos volitivos y cognitivos como hace SCHÜNEMANN con su concepto tipológico de dolo, de tal manera que la indiferencia tenga automáticamente un tratamiento distinto de la intención. Nunca me han interesado demasiado las discusiones puramente nominales sobre si el concepto básico del dolo se corresponde con el de primer grado o con el eventual. Ambos configuran un injusto doloso. Lo que pretendo resaltar es que las diferencias cuantitativas del caso concreto pueden quedar adecuadamente reflejadas a través de una adecuada teoría de la determinación de la pena, pero no me parece adecuado asumir como punto de partida que el dolo eventual tiene que ser siempre y necesariamente menos grave que el dolo directo ${ }^{21}$. El sujeto de

${ }^{21}$ FEIJOO SANCHEZ, CPC 98 -nota 3-, p. 313; el mismo, Retribución y prevención general, Buenos Aires y Montevideo, 2007, p. 683; FRISCH, Vorsatz und Risiko, Colonia, 1983, pp. 497 ss.; el mismo, Gegenwärtiger Stand und Zukunftsperspektiven der Strafzumessungsdogmatik, Zeitschrift für die gesamte Strafrechtswissenschaft 99 (1987), p. 769, coincidiendo en que no siempre el dolo directo se merece un tratamiento más grave que el dolo eventual; el mismo, Strafkonzept, Strafzumessungstatsachen und Masstäbe der Strafzumessung in der Rechtsprechung des Bundesgerichtshofs, en ROXIN/WIDMAIER (edits.), 50 Jahre Bundesgerichtshof, Festgabe aus der Wissenschaft, Tomo IV (Strafrecht, Strafprozessrecht); Munich, 2000, p. 290. De acuerdo en las conclusiones HÖRNLE, Tatproportionale Strafzumessung, Berlín, 1999, pp. 260 ss., 383 s., 391; Juristenzeitung 99, p. 1088 y Kriterien für 
Mejor no saber....más. Sobre la doctrina de la ceguera ...

personalidad psicopática que juega con el sufrimiento de su víctima, formando parte del juego que le excita si la víctima morirá o conseguirá sobrevivir a su macabro juego (una consecuencia de su acción posible, pero no segura o necesaria), no creo que se merezca menos pena que un homicidio con dolo directo, de primer o segundo grado. Es cierto, por poner todas las cartas sobre la mesa, que en el ejemplo que menciono hay otros elementos que configuran la gravedad del hecho (el ensañamiento en las lesiones o el atentado contra la integridad

die Herstellung von Tatproportionalität, en FRISCH/v. HIRSCH/ALBRECHT (edits.), Tatproportionalität. Normative und empirische Aspekte einer tatproportionalen Strafzumessung, Heidelberg, 2003, pp. 118, 127, aunque de acuerdo a su teoría expresiva de la pena orientada a las personas en la que prima la orientación a la víctima (Straftheorien, Tubinga, 2011, con exposiciones resumidas en Claus Roxins straftheoretischer Ansatz, en Festschrif für Claus Roxin zum 80. Geburtstag, Tomo 1, Berlín, 2011, pp. 19 ss. y passim y Gegenwärtige Strafbegründungstheorien: Die herkömmliche deutsche Diskussion, en v. HIRSCH./NEUMANN/SEELMANN, Strafe-Warum? Gegenwärtige Strafbegründungen im Lichte von Hegels Straftheorie, Baden-Baden, 2011, pp. 24 ss.) plantea una fundamentación basada en que para la víctima resulta más amenazante el dolo directo que el dolo eventual. HÖRNLE, Strafzumessung, pp. 217 ss., 390, considera, influenciada en este punto por SCHÜNEMANN, que la definición de un hecho como injusto, es decir, como conducta lesiva socialmente y la determinación de su gravedad a efectos de determinación de la pena debe hacerse desde la perspectiva de la víctima de acuerdo con un juicio normativo realizado por un observador razonable y, según esta autora, esta perspectiva de juicio es tan relevante para el desvalor del resultado (pp. 221 ss.) como para el desvalor de la acción (pp. 260 ss., 391). Sin embargo, tiene que reconocer que esta posición no permite justificar la diferencia radical de tratamiento del Derecho positivo entre el dolo eventual y la imprudencia consciente. Comparto, sin embargo, la idea de esta autora de que no tiene especial relevancia desde el punto de vista de determinación de la pena que el dolo directo se califique de primer o de segundo grado.

En contra de las conclusiones de HÖRNLE y, por tanto, del texto, AHLERS-GRZIBEK, Der normative Normalfall in der Strafzumessung, Hamburgo, 2003, pp. 144 s., considerando que todos los tipos de dolo deben ser tratados de forma idéntica a efectos de determinación de la pena en la medida en la que el Derecho positivo no haga distinciones. Esta parece ser a día de hoy la posición dominante en la doctrina alemana. 
moral), pero lo decisivo es que el dolo eventual con respecto a la muerte no se merece un tratamiento atenuado. En países como España, en los que los jueces suelen condenar a la mínima pena legalmente posible este tipo de distinciones se hacen difíciles, pero si establecemos la obligación de diferenciar punitivamente los casos de dolo directo de los de dolo eventual estamos creando un mayor problema de justicia que los que se derivan del tratamiento privilegiado de los autores imprudentes o con error vencible o evitable. El autor con dolo eventual toma una decisión a favor -eventualmente- del hecho desvalorado por la norma penal. Las razones o motivaciones de tal decisión son de lo más variado y no siempre el que actúa con dolo eventual se merece una menor pena que si hubiera realizado el hecho intencionadamente o con un conocimiento seguro o altamente probable de lo que va a suceder. Esto es evidente si se tiene en cuenta que la culpabilidad no es un concepto psicológico, sino estrictamente normativo y que la pena debe ser proporcional a la responsabilidad por el hecho. También si tenemos en cuenta la tenue diferencia de tratamiento que se merece la ejecución de una decisión con una representación segura o casi segura que convierte las consecuencias en necesarias (dolo directo) y la ejecución de una decisión con representación de unas consecuencias eventuales muy probables pero no con una probabilidad rayana en la certeza (dolo eventual). En todo caso, el trato proporcional depende, evidentemente, del concepto de injusto del que se parta.

\section{Propuesta personal: Sobre el fundamento de la diferenciación punitiva entre injusto doloso e imprudente ${ }^{22}$}

La cuestión esencial a dilucidar sigue siendo la razón por la que el injusto doloso es más grave que el imprudente, y eso, como señala correctamente el Prof. Ragués, tiene que ver con los propios fundamentos del Derecho Penal, lo que convierte el debate en interminable. Sin embargo, no creo que tenga que ver con el momento en el que hay que valorar la conducta, por lo que no se trata de un problema espe- 
cífico de ceguera provocada. Es decir, si consideramos que los casos de error evitable son menos desvalorables que los de representación insegura, esa valoración también se debe proyectar sobre las acciones que provocan la ceguera. Comparto con el Prof. Ragués la idea de que solo el "distinto contenido expresivo que se constata en las acciones y omisiones dolosas si se las compara con las imprudentes" representa un punto de partida adecuado para explicar esta característica esencial de nuestros ordenamientos, que tiene a su favor una amplia tradición histórica. No comparto, sin embargo, la idea de que el fundamento de la menor pena del delito imprudente radique en que la necesidad de pena forense es menos porque "el delincuente culposo se halla, por lo general, expuesto a sufrir una poena naturalis a resultas de su comportamiento" ${ }^{23}$. Existen tipos penales donde está totalmente excluida la amenaza de una poena naturalis como las falsedades imprudentes de funcionario, el blanqueo de capitales imprudente o los fraudes alimentarios nocivos imprudentes. Incluso en los delitos de resultado nucleares como el homicidio o las lesiones existen ámbitos donde no resulta excesivamente temible un autoperjuicio derivado directamente de la infracción del deber de cuidado como sucede, por ejemplo, con los accidentes laborales. Si éste fuera el argumento, bastaría con apreciar una atenuación genérica específica en los casos en los que el autor sufre consecuencias negativas como consecuencia directa de su actuación delictiva. Por otro lado, la amenaza de la poena naturalis no excluye la responsabilidad por dolo, como sucede en los casos de conductores suicidas-homicidas que pretenden ganar una apuesta. E1 propio JAKOBS me ha dicho personalmente en alguna ocasión que la teoría del Derecho Penal

${ }^{23}$ Este tipo de argumentos, como señala el Prof. Ragués en su trabajo, tienen su origen en JAKOBS (La normativización -nota 15-, pp. 81 ss. y ZStW 114 -nota 15-, pp. 593 ss.). Según este autor la pena en la imprudencia (no dirigida) es menor porque la poena naturalis hace de alternativa funcional parcial de la poena naturalis. Ya seguía los argumentos de JAKOBS para justificar normativamente la diferencia punitiva entre dolo e imprudencia en RAGUES I VALLES, El dolo y su prueba en el proceso penal, Barcelona, 1999, pp. 41 ss., $166 \mathrm{~s}$. 
puede dejar al margen de sus preocupaciones a los "desperados", pero me parece evidente que esta teoría falla no solo con los delincuentes-suicidas sino con todos aquellos que estén dispuestos a asumir situaciones irracionalmente extremas de riesgo no solo para terceros. En realidad, el Prof. JAKOBS tiene que recurrir al argumento de la poena naturalis porque si a todo autor infiel a la norma le corresponde una pena para confirmar la vigencia de la norma vulnerada, solo ha encontrado un fundamento para atenuar la pena en que la poena naturalis es menos necesaria en los casos normales de imprudencia para estabilizar la norma al existir otros factores que ayudan a estabilizarla. Pero no siempre que están presentes esos factores se atenúa la pena si el sujeto no ha actuado con base en un error, mientras si ha actuado por error se atenúa la pena aunque no estén presentes dichos factores adicionales que harían menos necesaria la pena. Creo que el sufrir una poena naturalis, es decir, ciertos perjuicios derivados directamente de una actuación delictiva (el violador contrae el SIDA, un ladrón se cae por una fachada y queda tetrapléjico, el conductor imprudente pierde a su familia en el accidente que provoca, etc.) puede hacer menos necesaria la pena en el caso concreto y se trata un tema que debe formar parte de una adecuada teoría de determinación de la pena, pero no es el aspecto que justifica el diferente tratamiento que dispensan nuestros ordenamientos a la responsabilidad por dolo y por imprudencia ${ }^{24}$. Existen casos que es evidente que no deben ser tratados como dolosos (con la pena más grave) y en los que no cabe temer ni un daño personal propio o de persona afín ni pérdida de prestigio social o profesional. Es solo el dato de que el autor actúa con una falsa representación de la realidad lo que provoca que el hecho adquiera una dimensión comunicativa distinta. Como reconoce el Prof. Ragués en su escrito, tal exposición a la pena natural no se da en todos los casos de imprudencia y es totalmente contingente. Es cierto, como señala en referencia a JAKOBS, que el Derecho Penal tiene que garantizar

24 FEIJOO SANCHEZ, CPC 98 -nota 3-,pp. 358 ss. De acuerdo HAVA GARCIA, La imprudencia inconsciente, Granada, 2002, pp. 55 s.; MANRIQUE PEREZ, (nota 2), pp. 102, 129. 
determinados niveles de gestión de riesgos, pero eso explica por qué es preventivamente necesaria la responsabilidad por imprudencia en determinados ámbitos delictivos, no su menor punición.

En la línea de mi concepción de la prevención estabilizadora, la pena debe ser proporcional a la lesividad social de la conducta. Y, si esto es así, las conductas imprudentes son menos lesivas para el desarrollo de la vida social (no individualmente para un determinado bien o consideradas global y estadísticamente) que las conductas dolosas equivalentes. El hecho imprudente es más tolerable desde la perspectiva de la pervivencia de la configuración del orden social. Ante un mismo hecho, la importancia social de los deberes que se infringen determinan la gravedad del injusto y, por tanto, de la pena. Son menos necesarias o más prescindibles las normas de cuidado, precaución o diligencia que las que establecen deberes directos de evitación (en forma de mandatos o prohibiciones). Sería más difícil, pero no imposible, que las sociedades modernas mantuvieran sus dinámicas actuales desterrando la responsabilidad imprudente de las leyes penales, pero sería imposible vivir en una sociedad en la que quedaran sin castigo los homicidios y las lesiones dolosas. Para mantener la actual configuración de la vida social es más necesaria la estabilización de prohibiciones o mandatos directos en las que la actuación del sujeto ya no se basa en un error.

Lo decisivo a efectos de imputación jurídico-penal no es que el sujeto quiera infringir un deber, sino que exista una "decisión contraria a deber", y por ello la diferencia entre el injusto doloso y el imprudente depende de la relevancia social de los deberes. En este sentido, cuando la norma describe un hecho como típico, de esa descripción se deriva un deber directo o inmediato de evitación, que es el que caracteriza al delito doloso. Los órdenes sociales más primitivos castigan básicamente conductas dolosas, pero a medida que se van haciendo más complejos y tecnificados precisan a veces otros deberes complementarios de evitación más indirectos o mediatos: los deberes de cuidado; de esta manera, se va asentando la responsabilidad penal por imprudencia (que, ciertamente, posibilitar garantizar determinados niveles de gestión cuidadosa de riesgos, imprescindibles en una 
sociedad tecnificada y con una intensa especialización profesional). Sin embargo, por muy complejos que se acaben volviendo los órdenes sociales, los deberes originales o primigenios (prohibido matar) que forman parte del código genético de la vida en sociedad siguen siendo funcionalmente más importantes para la pervivencia del orden social, por lo que su violación es mucho más perturbadora socialmente y su infracción se ha de ver en consecuencia castigada con mayor pena.

Desde una perspectiva comunicativa basada en la relevancia de los deberes para la sociedad se puede encontrar, por lo tanto, una fundamentación de la distinción punitiva entre dolo e imprudencia. Ello, además, es plenamente coherente con otros factores de determinación de la pena relacionados con la responsabilidad subjetiva en el ámbito de la imprudencia ${ }^{25}$. Es legítimo, por lo tanto, imponer mayor pena al que se le imputa la infracción de un deber más importante para la sociedad $^{26}$, por lo que su hecho resulta más perturbador.

No comparto, por consiguiente, la perspectiva de que "la pena debe intentar provocar, asimismo, el fracaso del infractor ante la colectividad, lo que exige consecuencias más severas frente a quien ha realizado su propósito destructor del interés protegido (dolo directo de primer grado) y, por tanto, ha alcanzado su objetivo, que ante quien simplemente ha dañado dicho interés como un efecto colateral de su comportamiento (dolo eventual o imprudencia)". Como ya he expuesto, la lesividad de la conducta no depende tanto de la intención del autor como de la importancia de los deberes que infringe. Aquél que, aunque con dudas, inseguridades o incertidumbres "tiene el tipo penal ante los ojos" y decide seguir adelante (o no actuar en los casos de omisión) manifiesta una hostilidad o indiferencia más grave que el que infringe su deber de cuidado pero no

${ }^{25}$ Las teorías más psicológicas siempre han tenido problemas graves para armonizar la distinción imprudencia con representación/sin representación con la gravedad de la pena. En tiempos recientes se plantean, por ejemplo, esos problemas tradicionales en la concepción psicologicista de SACHER, (nota 15), p. 257.

${ }^{26}$ Sobre los argumentos que se han ofrecido en la doctrina alemana para fundamentar el mayor desvalor del injusto doloso vid. por todos, en profundidad, SACHER, (nota 15), pp. 155 ss., centrándose en los dos autores que, en mi opinión, han trabajado con mayor profundidad estas cuestiones: FRISCH y JAKOBS. 
Mejor no saber....más. Sobre la doctrina de la ceguera ...

tiene el tipo ante los ojos. El dolo eventual es dolo porque el autor con dolo eventual infringe la misma prohibición o mandato que el que actúa con dolo directo. La mayor o menor intensidad de sus voliciones con respecto al hecho típico es un aspecto secundario. Lo decisivo a efectos de imputación es lo que expresa intersubjetivamente, no sus fines o intenciones ${ }^{27}$. No encuentro un tercer lugar intermedio para la

${ }^{27}$ En sentido contrario, MANRIQUE PEREZ, (nota 2), pp. 105, 121, 229, 242 ss., 265 ss. y passim. Esta autora pretende desde la filosofía moral defender un diferente tratamiento jurídico-penal de la intención y de la previsión de consecuencias identificando dolo e intención en la medida en la que considera que existe una diferencia moral entre intentar y prever, a pesar de que reconoce que planteamientos como el mío se corresponden con "la actitud dominante en la dogmática contemporánea" (p. 115). Cuando me critica que "una versión normativizadora del dolo tendría que mostrar por qué razón no podemos limitar el dolo a las intenciones efectivas del agente" la respuesta es sencilla: porque el sistema jurídico no lo hace (por ello a veces existen tipos que exigen expresamente dolo directo y excluyen el dolo eventual). Mencionando un ejemplo suyo, en el fútbol no solo está prohibido tocar intencionalmente el balón con la mano (pp. $121 \mathrm{~s}$.). El que salta en el área con los brazos abiertos de espaldas o de lado para evitar un tiro o un centro tocando el balón con la mano comete penalty aunque esa no fuera su intención. Es la norma y no la intención del jugador las que establece lo que se puede y no se puede hacer y ello se hace para facilitar el desarrollo del juego y en función de las necesidades del mismo. La identificación de los supuestos en los que se debe pitar penalty o en los que los hechos delictivos se deben castigar de forma más grave no depende de lo que quiera el agente, sino de la atribución de sentido por parte de la sociedad a través de sistemas especializados como el sistema jurídico. Lo decisivo en Derecho no es la razón por la que actúa el sujeto (que podría afectar a una disminución de la culpabilidad en todo caso), de tal manera que solo haya dolo cuando sus razones son totalmente delictivas, sino que las normas son razones para actuar $\mathrm{u}$ omitir.

La perspectiva de racionalidad subjetiva de MANRIQUE hace tiempo que fue abandonada por la doctrina jurídico-penal con buenas razones y ni siquiera los kantianos liberales como KÖHLER o ZACZYK mantienen en la actualidad posiciones tan estrictas sobre la vinculación del Derecho a las intenciones del autor, de tal manera que solo se puede atribuir responsabilidad por lo que se intenta. Cfr. por diversos lugares KÖHLER La imputación subjetiva: estado de la cuestión, en VARIOS AUTORES, Sobre el estado de la teoría del delito, Madrid, 2000, pp. 83 ss. Si, como afirma esta autora, la figura del dolo eventual responsabiliza a los agentes "por las consecuencias que ocasionaron y no 
infracción de otro tipo de deber. El tipo objetivo en los casos de responsabilidad dolosa e imprudente es el mismo, por lo que el diferente tratamiento que el ordenamiento dispensa a ambos injustos estriba en la diversa relevancia de los deberes que se infringen. No veo que el autor que actúa con una representación segura o casi segura cometa un injusto distinto que el que lo hace con una representación con dudas, mientras sí veo una diferencia clara cuando el autor tiene una representación errónea y su injusto se basa en la infracción de un deber de cuidado, que es un deber de evitación del hecho típico más indirecto que el que caracteriza los injustos dolosos.

La exposición realizada está en consonancia con mi concepción normativa. El desvalor de la conducta dolosa no reside en el conocimiento o la representación del infractor, eso son solo datos fácticos. El fundamento del mayor desvalor se encuentra en la decisión de realizar u omitir a pesar de lo que se conoce. Dolo no es igual a conocimiento, sino que la distinción entre injusto doloso e imprudente tiene sentido en relación al horizonte de representaciones de los que realizan la conducta típica porque las normas penales regulan conductas humanas. La diferencia normativa relevante no se encuentra en las características psicológicas de la acción, sino en la infracción de deberes diferentes; la pena está vinculada a la importancia que para una determinada sociedad tengan esos deberes (al igual que es más importante la prohibición de matar que la de robar). Puede ser que en el marco de la determinación de la pena existan datos de la conducta que le otorguen un significado comunicativo al hecho que

por lo que hicieron" (p. 133), "en el caso de atribución de responsabilidad a título de dolo eventual no hay un reproche por aquello que el agente intenta hacer sino únicamente por aquello a lo que el individuo dará lugar mediante su acción" (p. 134) y "la responsabilidad se desplaza desde el ámbito de lo que hacemos hacia la esfera de lo que ocurre", no solo debería castigarse menos, sino dejarse sin castigo al no tratarse de una acción culpable sino solo responsabilidad objetiva por las consecuencias. Por ello esta autora entiende que el reproche por dolo eventual podría quedar justificado sobre la base de otro tipo de exigencias como" la mayor eficiencia en la persecución penal" o la "revalorización de la responsabilidad objetiva". 
Mejor no saber....más. Sobre la doctrina de la ceguera ...

se merezca un adecuado reflejo normativo y punitivo, pero ello no depende rígidamente de la vinculación volitiva o afectiva del infractor con el hecho.

La mera idea de indiferencia, sin un adecuado tratamiento del elemento cognitivo e intelectual de tal indiferencia, acaba diluyendo elementos de distinción básicos entre responsabilidad dolosa ("indiferencia total") e imprudente ("indiferencia relativa") ${ }^{28}$. La imprudencia es también indiferencia con respecto al bien jurídico, solo que a través de la vulneración de la norma de cuidado. No solo creo que sea teóricamente erróneo centrar el desvalor de la conducta en la indiferencia frente al bien jurídico protegido, sino que tiene peligrosas consecuencias. Una de ellas es que, en algunas ocasiones, la jurisprudencia española, basándose en un peligroso cóctel que tiene como ingredientes la indiferencia del autor frente al bien jurídico y su peculiar visión de la "ignorancia deliberada", ha venido considerando que la infracción grave de deberes profesionales de conocimiento (por ejemplo, identificación de una operación como blanqueo) debe ser tratada como dolo, castigando de esta manera conductas imprudentes como dolosas. Ya hace tiempo que razones como estas llevaron a la doctrina dominante a rechazar la interesante "teoría de la indiferencia frente a la lesión" de ENGISCH ${ }^{29}$, basada en su concepción de la "culpabilidad por el carácter" tan influenciada por el determinismo de

${ }^{28}$ Por ejemplo, SACHER, (nota 15), pp. 180, 246 s. y passim, en la línea del concepto tipológico de dolo de su maestro SCHÜNEMANN que pondera fenomenológicamente los contrapesos del elemento intelectual y del elemento volitivo entendido como ánimo de enemistad hacia el bien jurídico (Temas actuales -nota 15-, pp. 106 ss.; Chengchi Law Review 94 -nota 15-, pp. 266 ss.) asume el dolo eventual en los supuestos en los que solo existe la representación de la posibilidad de la realización del tipo acompañada con una indefinida posición de indiferencia frente al bien jurídico por parte del autor. De esta manera se corre el peligro de extender muchísimo el alcance del dolo y de abrir las compuertas al arbitrio judicial en la línea de la doctrina jurisprudencial española de la "ignorancia deliberada".

${ }^{29}$ En contra de esta teoría, FEIJOO SANCHEZ, CPC 98, p. 296, nota 67, con abundantes referencias a las críticas recibidas por esta variante de la "teoría del consentimiento" propuesta por ENGISCH. 
SCHOPENHAUER $^{30}$. Da la impresión de que un sector de la doctrina pretende volver por derroteros similares estableciendo diferencias tripartitas $^{31}$.

\section{Reflexión final: el camino que la doctrina tiene por delante}

En la medida en la que la distinción entre el delito doloso y el delito imprudente no tiene naturaleza ontológica, siempre estaré de acuerdo en "reflexionar acerca de la necesidad de replantear un sistema de imputación subjetiva basado exclusivamente en la distinción entre dolo e imprudencia o, cuando menos, para revisar las consecuencias jurídicas que se asocian a cada una de estas figuras". La imputación subjetiva del hecho típico no se reduce a ser un una mero reflejo de procesos psicológicos. Error y conocimiento no son más que hechos psíquicos que suponen el sustrato de la imputación jurídico-penal, pero no existe una armonía preestablecida y previa al Derecho que vincule la decisión valorativa sobre cómo deben ser tratados jurídicamente ${ }^{32}$. Sin embargo, sigo creyendo que en el contexto cultural actual sigue siendo adecuada una diferenciación valorativa entre conocimiento y error y que la distinción penológica entre comisión dolosa y comisión imprudente está justificada por la diferente entidad de los deberes que dan lugar a cada una de ambas modalidades delictivas. No veo lugar para un injusto intermedio. Al menos no he

${ }^{30}$ Derecho Penal y neurociencias. ¿Una relación tormentosa?, InDret Penal 2/2011, pp. 5 s.

${ }^{31}$ Sobre este tema FEIJOO SANCHEZ, La imprudencia en el Código Penal de 1995 (cuestiones de lege data y de lege ferenda), CPC 97, pp. 347 ss., especialmente en contra de las tesis de SCHÜNEMANN.

${ }^{32}$ De hecho todo lo dicho vale solo para la "ceguera antes los hechos". En la "ceguera voluntaria o por indiferencia ante el Derecho" no aprecio razones para la atenuación o un tratamiento privilegiado como el del art. 14.3 CP que solo conduce a una total separación entre ley y praxis judicial, de tal manera que muchas sentencias niegan el error de prohibición o mandato cuando se puede apreciar que lo que niegan es que el error pueda disculpar de alguna manera al infractor. El desarrollo de este tema nos llevaría, sin embargo, demasiado lejos del tratamiento de la ceguera voluntaria ante los hechos como tema central. 
acertado a encontrar una alternativa mejor teniendo en cuenta todos los elementos a ponderar. Lo que sí cabe revisar son las enormes diferencias de trato punitivo (enormes reducciones de pena, impunidad, etc.) que se establecen entre conductas que, a veces, no presentan desvalores tan diferenciados y que derivan de la distinción cualitativa entre responsabilidad dolosa o imprudente. En mi opinión, la solución no está en modificar el concepto de dolo, sino en ampliar puntualmente el alcance de la responsabilidad imprudente, pero este es un tema que precisa todavía muchas clarificaciones y existen muchas posibilidades abiertas.

Estoy convencido de que en el estado actual de la dogmática del dolo la mayor o menor vinculación intelectual del individuo con el hecho sea la cuestión decisiva, sino más bien es preciso trabajar más en el objeto del dolo, es decir, qué es aquello que el sujeto ha de representarse para poder hablar de un delito doloso, especialmente en los casos de participación $\mathrm{y}$ en aquellos casos en los que alguien asume un papel muy concreto en una organización de un hecho delictivo dominada o controlada por otros. En mi opinión, la solución sigue estando en un concepto normativo de dolo con el que se viene trabajando en gran cantidad de sentencias y que ha permitido renovar los criterios jurisprudenciales en un corto espacio de tiempo ${ }^{33}$, pero siempre respetando los límites que establece el principio de legalidad y principios estructurales básicos del Estado de Derecho como el principio de presunción de inocencia. Cuando tocamos las fibras más sensibles del sistema jurídico hay que tener en cuenta los equilibrios (homeostasis). En esta línea de normativización del dolo el Prof. Ragués ha realizado contribuciones de gran relevancia e interés desde su tesis doctoral. Espero que los cantos de sirena desde la orilla de la "ignorancia deliberada" no le desvíen de una sólida andadura que le han convertido en un referente para muchos que admiramos su obra científica.

${ }^{33}$ SSTS 890/2010, de 8 de octubre; 1187/2011, de 2 de noviembre; 384/2012, de 9 de mayo (de todas ellas ponente Alberto Jorge Barreiro), en una línea que inició la Sentencia del Tribunal Supremo de 23 de abril de 1992 sobre el envenenamiento masivo con aceite de colza manipulado. 